\title{
Contributions to Géotechnique 1948-2008: Constitutive and numerical modelling
}

\section{ZDRAVKOVIC* and J. CARTER $\dagger$}

\begin{abstract}
A review of the first 60 years of Géotechnique publications shows clearly how the subject of soil mechanics has evolved. In terms of constitutive and numerical modelling of soil, early forms of numerical analysis involved hand calculations of ultimate states applying classical methods of analysis: limit equilibrium, limit analysis or stress field solutions. Consequently, the soil was considered to behave as a rigid plastic material, and to follow one of the two basic failure laws of classical soil mechanics, namely the Tresca or Mohr-Coulomb failure criteria. For assessing the deformation of structures, soil was normally considered to be linear elastic. The foundations of modern numerical analysis and constitutive modelling were laid in the early to mid 1960s, with the development of the finite element method and the postulation of the critical state framework of soil behaviour respectively. Clearly, the continuous advancement of computer power has been essential in applying new developments to modern geotechnical analysis. This paper reviews some of the main milestones in the evolution of geotechnical analysis in the past 60 years, commenting, where appropriate, on what problems still lie ahead.
\end{abstract}

KEYWORDS: constitutive relations; historical review; numerical modelling and analysis; theoretical analysis
Un examen des 60 premières années de publications de Géotechnique démontre clairement l'évolution suivie par la discipline de la mécanique des sols. En ce qui concerne la modélisation constitutive et numérique des sols, les premières formes d'analyse numérique comportaient des calculs manuels d'états limites avec l'application de méthodes d'analyse classiques : équilibre limite, analyse limite ou solutions sur place pour les contraintes. C'est ainsi que l'on estimait que le sol se comportait comme une matière plastique rigide en suivant une des deux lois de base sur la rupture de la mécanique des sols classique, à savoir les critères de rupture de Tresca ou de MohrCoulomb. Pour l'évaluation de la déformation des structures, le sol était normalement considéré comme étant élastique linéaire. C'est vers le début ou la moitié des années soixante que l'on posa les fondations de l'analyse numérique et de la modélisation constitutive modernes, avec le développement de la méthode aux éléments finis et la postulation du cadre de l'état critique respectivement dans le comportement des sols. Le progrès continu de l'informatique a joué manifestement un rôle essentiel dans l'application de nouveaux développements dans l'analyse géotechnique moderne. La présente communication passe en revue les principales étapes de l'évolution de l'analyse géotechnique au cours des 60 dernières années, en se penchant, le cas échéant, sur les problèmes que l'on devra affronter dans l'avenir.

\section{THE BEGINNINGS}

From reviewing Géotechnique issues published in the past 60 years, it is evident that the first 10 years of the journal reported mainly case studies, ground investigations, and the development of experimental techniques. The first numerical procedure reported in Géotechnique was Bishop's method of slices calculation for slope stability, with a circular slip surface (Bishop, 1955). After the method of Fellenius developed 20 years earlier, this was the starting point for the development of future similar procedures that are still used in engineering practice. Any calculations at that time were performed by hand, and were therefore time consuming. The first account of this, as well as of the first use of a computer, is reported in relation to Bishop's method of slices by Little \& Price (1958), who state that for 200 circles, each with about 30 slices, for a $150 \mathrm{ft}$ high dam 'a team of four (people) took more than 4 weeks to complete the calculation.' 'With the powerful new weapon of the electronic computer' it took less than half an hour for all 200 circles, and the cost of the analysis per circle was reduced from $£ 4$ to 2 shillings (10 pence in new money)! At the same time, however, the authors warn that with any future use of computers 'it will be necessary to guard against over-enthusiasm for complicated methods of analysis where there is a

Discussion on this paper closes on 1 December 2008, for further details see $\mathrm{p}$. ii.

* Imperial College London, UK

$\uparrow$ The University of Newcastle, Australia. danger that limitations of accuracy in measuring soils and other properties will be forgotten.' A far-reaching message that, unfortunately, still applies!

In terms of constitutive modelling, early accounts of the analyses of boundary value problems considered the soil to be either linear elastic or rigid plastic, following the basic failure criteria of Tresca or Mohr-Coulomb. The first realistic framework that had an enormous influence on the development of modern constitutive modelling, and which continues to do so today, is the critical state framework, introduced by Roscoe et al. (1958). This paper shows the analysis of a consistent set of clay data, from both drained and undrained experiments, that forms a framework for the yielding of clays. For the first time in Géotechnique we read about the concept of the 'critical voids ratio', which answers the authors' question as to whether the loading path ends at any specific point. The paper also shows an isometric view of the yield surface for Weald clay, which combines Hvorslev and what will later become Roscoe surfaces. Experiments by Henkel (1960) on the same clay show further evidence of the unique relationship between the mean effective stress, shear strength and water content at failure, contributing further to the validity of the critical state concept. This framework is still the most dominant one in constitutive modelling of soils.

In terms of numerical analysis, the early 1960s saw the development of finite difference procedures to look at consolidation and seepage through elastic soil (e.g. Gibson, 1958; Tomlin, 1966). Numerical analysis of geotechnical 
problems started to develop with the development of finite element techniques, first reported in Géotechnique by Zienkiewicz et al. (1968). Having published his first book on finite elements in 1967, in this paper for the first time a discretisation of a soil domain is shown, applying triangular finite elements. The aim was to determine zones of tensile principal stress in an elastic rock mass around tunnel excavations or in foundations underneath a dam. As the material cannot take tension, the paper describes a possible method for modelling stress transfer from zones where tension occurs. Dealing with 'no tension' in soils is still not straightforward, and current computer programs employ different procedures and conditions to account for tension.

Other solutions of geotechnical problems in this period have mainly considered the soil to be linear elastic. Typically, parametric analyses were performed, on the basis of which suitable design charts or interaction diagrams were produced to aid engineering design. For example, Milovic et al. (1970), using the finite element method, produced charts for stress distributions in an isotropic elastic medium underneath rigid and rough strip footings, due to an applied inclined load on the footing at a certain eccentricity. Poulos \& Davis (1968) and Poulos (1968) produced comprehensive studies on settlement of a single incompressible pile and then on settlement interaction between two identical piles and pile groups in an elastic soil, utilising Mindlin's equations. Results were presented in terms of charts that plot load distribution in a single pile, load and settlement distribution between the piles, all with respect to pile length to diameter ratio and for different values of the Poisson's ratio. These studies formed the basis of subsequent developments in pile interaction analyses, some of which are in use even today.

Another important advance in the application of the linear elastic soil model to foundation problems was first published by Gibson (1967), with a later, more comprehensive, summary provided in his Rankine Lecture (Gibson, 1974). In this body of work the soil, while being represented as an elastic continuum, had the important distinction of an elastic modulus that varied linearly with depth below the soil surface. In this way an attempt was made to provide a more realistic model of natural soils, where this type of depth effect is well known, and where it is generally acknowledged that soil stiffness does increase with depth. In particular, it was shown by Gibson that for the case of an incompressible half space the loaded surface settles by an amount proportional to the local intensity of applied pressure, where the constant of proportionality (effectively the coefficient of subgrade reaction) is independent of the size or shape of the loaded area and equal numerically to twice the rate of increase of Young's modulus with depth. While it is likely that this work was initially inspired by the desire to provide more reliable predictions of the behaviour of foundations on soils such as London Clay, it is worth noting that the model has much wider application.

Clearly, in any numerical analysis, such as the finite element method, a linear elastic behaviour does not require special incremental solution procedures. The stress-strain relationship is linear, and therefore the stiffness matrix in the system of equations does not change over a load step. This is not the case when soil behaviour is considered to be non-linear elasto-plastic. In such a situation the stiffness matrix varies along the loading path, and the solution of the problem must be determined in an incremental manner. For the first time in Géotechnique a solution of an elasto-plastic problem was reported by Smith (1970), who used the initial strain method for incremental solution. The problem analysed was a thick cylinder loaded uniformly over its inner perimeter, for which there is an analytical solution that is used for comparison with the numerical results. At the same time the research group at Swansea developed an elastic viscoplastic approach for soil behaviour, where classical soil plasticity was represented with viscoplastic, rather than purely plastic, strains. They also developed an algorithm for the incremental solution as a viscoplastic problem, and Zienkiewicz et al. (1975) presented a viscoplastic formulation of some constitutive models commonly used in geotechnical finite element analysis (Mohr-Coulomb and modified Cam Clay). They also showed analysis results for some boundary value problems simulated with these models, which were solved with a viscoplastic non-linear solution algorithm. However, at present, almost 30 years later, there is still no unified opinion as to which non-linear solver is the most efficient and accurate in solving geotechnical problems. Existing computer programs use either viscoplastic or tangent stiffness, or modified and full NewtonRaphson approaches.

Apart from constitutive models and solution procedures, the finite element method of analysis requires the truncation of a continuum to a domain of a manageable size for implementation in the analysis. Using examples of idealised slopes Smith \& Hobbs (1974) investigated the effect of the size (i.e. distance to far boundaries) and coarseness of the mesh on analysis results. They concluded that the far boundaries should be sufficiently far away from the problem and that the mesh should be finer in the areas of high stress concentration. This advice still applies in non-linear elastoplastic geotechnical analysis. The authors also performed plane-strain analyses of centrifuge model slopes, using the von Mises constitutive model, and obtained higher failure heights than those observed in experiments. Without explaining why, the authors state that 'if the Tresca criterion were used, rather than the von Mises, lower collapse loads would result.' A possible reason for this is that the von Mises circle is circumscribed around the Tresca hexagon in the deviatoric plane (in stress space), with the input strength being fixed to that in triaxial compression. As the problem involves failure under plane-strain conditions, the von Mises circle mobilises a higher strength than that given by the Tresca hexagon, and hence enables higher failure heights. It is important to note that this problem is not fully recognised by some numerical analysts even today. Although the von Mises and DruckerPrager yield surfaces are easier for implementation in a finite element code, owing to the absence of corners, care must be taken when choosing input parameters. Further to this, Smith \& Hobbs (1976) showed an extension of the finite element method to incorporate consolidation in the soil, coupling its mechanical and hydraulic behaviour. Biot's theory of consolidation was implemented in a finite element program and applied to the analysis of embankments on soft ground, where the predicted settlement of the foundation soil with time agreed well with observations. A further parametric study investigated the effect of embankment stiffness on pore pressures generated in the foundation soil. This development was an important step towards general application of numerical analysis in geotechnics, as most real situations involve transient soil behaviour, rather than purely drained or purely undrained conditions, which are possible to analyse without recourse to a coupled formulation.

\section{MODERN CONSTITUTIVE MODELLING Clays}

In terms of constitutive models, after postulation of the critical state framework, the development of the most widely used critical state model, the modified Cam clay (MCC) model, in 1968 was not reported first in Géotechnique. However, several subsequent extensions to the MCC model 
reported in Géotechnique papers tried to improve the behaviour of the model below the yield surface, which is assumed to be elastic in the original model. It was recognised that real soils do not behave in this manner, and, for example, Pender (1978) made an assumption that undrained stress paths below yield are of a parabolic shape, therefore being non-linear instead of linear as in the original model. Van Eekelen \& Potts (1978) introduced several improvements to the model:

(a) a cut-off surface on the dry side to reduce the mobilised peak strength of overconsolidated soils

(b) a Mohr-Coulomb yield surface in the deviatoric plane to better represent soil failure

(c) non-associated plasticity in the deviatoric plane, with circular plastic potential surface

(d) a single parameter cyclic model below the yield surface to enable modelling of cyclic processes.

In general, it is an established procedure even today to improve simple elasto-plastic constitutive models (of MohrCoulomb or MCC type) by coupling them with simple nonlinear models, which then replace the elastic behaviour of the elasto-plastic model.

As laboratory testing became more advanced in the 1980s, more was understood about the small-strain stiffness behaviour of soils in the range of up to $1 \%$ strain. Simple models were developed to reproduce stiffness degradation from the initial elastic plateau. However, they did not have a firm theoretical framework, but were simple curve-fitting techniques that could be coupled with plastic models. In this category Simpson et al. (1979) presented a model for London Clay (the LC model) developed in strain space, which can account for stiffness variation with both stress and strain level. The authors demonstrated for the first time in Géotechnique the importance of modelling small-strain stiffness non-linearity in soil-structure interaction problems at serviceability limit states, by back-analysing some excavations in London Clay. Subsequently, Simpson (1992), talking about the design of retaining walls in his Rankine Lecture, presented his ideas of a 'brick' model, in which soil stiffness behaviour is represented as that of a brick on strings. The stiffness degradation curve was presented in a stepwise manner, each step corresponding to a string length (strain), and proportion of stiffness compared with the maximum one. Further to this, Jardine et al. (1986) presented a different empirical model for small-strain stiffness degradation with stress and strain level and applied it in the analysis of a number of boundary value problems (footing, strutted excavation, axially loaded pile). They demonstrated that results of soil-structure interaction problems using linear (instead of non-linear) elasticity can be misleading. All these developments led to a very positive outcome for geotechnical practice in the UK and elsewhere, as the necessity of modelling small-strain non-linearity at serviceability limit states is today very well understood, and designers are trying to incorporate these models in their finite element programs. The appeal of these simple models is that they need only a stiffness degradation curve for calibrating input parameters, and are then coupled with a suitable plastic model.

The next major step in the development of a sound constitutive framework was the introduction of kinematic yield surfaces below a critical state bounding surface, reported in Géotechnique first by Mroz et al. (1979). The bounding surface has the same elliptical shape as the MCC yield surface in the deviatoric stress-mean effective stress plane, but the behaviour below it is elasto-plastic, and this surface now presents a gross yield locus. A small kinematic surface, which is of the same shape as the bounding surface, encompasses truly elastic soil behaviour, and as the stress state engages this surface and moves on its way to the bounding surface, elasto-plastic behaviour is invoked. Both isotropic and kinematic hardening exist, and certain rules must be satisfied for the movement and interaction of these surfaces. With this concept, stress path non-linearity and plasticity, as well as small-strain stiffness degradation below gross yield, can be simulated. Although it is capable of simulating some of the most important aspects of real soil behaviour, the application of this modelling framework has become increasingly popular only in the past 10 years, as the importance of simulating small-strain behaviour became more appreciated. Many such model formulations appeared in Géotechnique, starting with Stallebrass \& Taylor (1997), who presented a model with two kinematic surfaces: a yield surface, which is a boundary of elasticity; and a history surface. Simulating laboratory experiments on kaolin, the authors demonstrated the model's capability in dealing with the effects of recent stress history and stress path direction. Various further similar models introduced the effects of structure and de-structuration in soils (e.g. Kavvadas \& Amorosi, 2000; Rouainia \& Muir Wood, 2000; Baudet \& Stallebrass, 2004). At present, the kinematic surface framework appears to be a way forward in the future constitutive modelling of clays, but a number of issues still have to be resolved for its use in successful modelling of overconsolidated clays.

Other aspects of clay behaviour, such as strength anisotropy, creep and partial saturation, have been addressed in a number of new models based on a critical state framework, in which the shape of the yield or the bounding surface is still the ellipse of the MCC model. Of these, arguably the first significant breakthrough in modelling unsaturated clays using a rigorous applied mechanics approach came from Alonso et al. (1990), with the formulation of the Barcelona Basic Model (BBM). This model utilises hardening plasticity and two independent stress variables: the excess of total stress over air pressure, and the suction. It accounts for the stiffness changes of the soil induced by suction change, reproduces the irreversible response of the soil on stress and suction reversals, and simulates collapsible soil behaviour. The model is relatively simple because of its need for only a modest amount of experimental data to determine the input parameters, and it is suitable for unsaturated soils of moderate to low plasticity. This was the starting framework for future similar model developments, for example those of Wheeler \& Sivakumar (1995) and Bolzon et al. (1996). However, it should be noted that others, e.g. Khalili \& Kabaz (1998), contend that the effective stress approach for unsaturated soils originally proposed by Bishop has some advantages over the use of two independent stress variables.

Whittle (1993) presented a critical state bounding surface plasticity model for clays, the MIT-E3 model, which can simulate non-linearity and plasticity below gross yield, similar to the kinematic surface models. In addition, one of the hardening rules of this model allows the rotation of the bounding surface in general stress space, and the model can therefore simulate both inherent and induced anisotropy of clays. This is arguably the most advanced, but also the most complex, model that can deal with this aspect of soil behaviour. Borja \& Kavazanjian (1985) reported for the first time in Géotechnique a constitutive model for time-related soil behaviour. Here, the total strain consists of elastic and plastic time-independent strains, evaluated from the MCC yield surface, and time-dependent plastic strains, evaluated from creep rate expressions empirically derived from triaxial tests. However, it is the model of Yin \& Graham (1996), which introduces the equivalent time concept, that makes a step forward in modelling creep. Although this paper showed model development for one-dimensional consolidation only 
(a complete model was published later, but not in Géotechni$q u e$ ), it assumed that the total strain consists of elastic and viscoplastic parts. The use of equivalent time allows the model to have stress-strain-equivalent time states independent of stress path (i.e. total strain rate is equal to creep strain rate). The model also introduces the limit time line, which helps to model soils that do not experience creep: that is, if the equivalent time is set to be very large (infinity), the creep rate will be equal to zero.

\section{Sands}

Modelling of sands was significantly advanced by the formal introduction of the state parameter concept by Been \& Jefferis (1985), although the 'distance' between the state of the sample and the ultimate critical state was first mentioned in Géotechnique by Wroth \& Bassett (1965). This is a fundamental physical concept for describing the behaviour of sands, as it combines the influence of void ratio and stress level with respect to the critical state conditions. A constitutive model that makes use of this concept for the first time in Géotechnique is that of Manzari \& Dafalias (1997). This model consists of three conical surfaces that have the shape of a smooth triangle in the deviatoric plane: they are the dilatancy, critical state and bounding surfaces. It also includes a kinematic yield surface, which is a circular cone and which limits the elastic zone in the material. If the initial value of the state parameter is positive, this implies that the sand will dilate, passing through phase transformation upon reaching the dilatancy surface, engaging peak on the bounding surface, and then slowly approaching the critical state surface. If this value is negative, the sand will contract, failing along the critical state surface (which now coincides with the bounding surface) and never engaging the dilatancy surface. Because of the small elastic yield surface, the model also mobilises plasticity before the gross yield, and can simulate cyclic loading of sands. Several extensions of this model (not published in Géotechnique) improve its cyclic behaviour, in particular, but the main concept is maintained.

Modelling of granular materials has also been attempted through the Cosserat approach, which looks at the microstructure of granular materials within the continuum approach. An example of such an approach was published in Géotechnique by Muhlhaus \& Vardoulakis (1987), who developed a two-dimensional Cosserat theory for a granular material consisting of rods of the same diameter, adopting aspects of slip and rotation between individual rods. To be able to predict the dimensions of the shear band, the grain size must be introduced into the constitutive model, which is not the case in continuum models. The results show that the width of the shear band depends only on the grain size, and not on the geometry of the soil body, which could be useful when trying to analyse progressive failure in soils in general.

Another, more widespread, development in modelling granular materials is the concept of distinct element modelling, where the behaviour of individual grains and intergranular contacts is introduced, instead of treating the soil as a continuum. The first such application was presented by Cundal \& Strack (1979), who described a numerical procedure for simulating the behaviour of assemblies of discs and spheres. The method utilises an explicit solution scheme, where the motion of particles is described by a dynamic equation, taking account of the inertia of the discs. The computer program BALL was written, and numerical results were compared with photoelastic tests on an assembly of discs, showing good agreement of force chains through particle contacts between numerical and experimental results. Thornton (1979), using discrete element modelling, examined the strength of a close-packed regular (face-centred cubic) array of uniform rigid spheres, allowing for the first time three degrees of rotational freedom for the system of particles. This work showed agreement with Lade's experimental failure envelopes for sand.

Clearly, modelling grains as circular discs and spheres is quite idealistic, and attempts have since been made to account for more realistic grain shapes. Among these, Lin \& $\mathrm{Ng}$ (1997) presented three-dimensional discrete element modelling using random arrays of elastic ellipsoidal particles, with a new numerical algorithm for contact detection of these particles. By comparing the results from single-sized spherical and single-sized ellipsoidal particles, they were able to reproduce some important effects of particle shape: ellipsoidal particles achieve lower porosity under the same consolidation procedure; in triaxial compression they also achieve higher strength, larger initial modulus, more dilation and less particle rotation, which are all aspects observed when comparing experimental results from rounded and angular sand grains. Latham et al. (2001) went even further, developing tetrahedral particle shapes, with which they were able to investigate the effects of particle orientation, as this influences the interlocking potential of the granular structure. Finally, Cheng et al. (2003) described the use of distinct element modelling in simulating the behaviour of crushable materials, utilising spherical particles. This is achieved by modelling a grain as an agglomerate of bonded spheres.

The main use of distinct element modelling has so far been in simulating laboratory experiments and understanding material response from the micromechanical point of view (e.g. Thornton, 2000; Cui \& O'Sullivan, 2006; Zhang \& Thornton, 2007).

All constitutive model developments reviewed so far have been performed within the concepts of classical plasticity. Géotechnique also reported the work of Collins \& Kelly (2002), who applied the principles of thermomechanics in developing a systematic procedure for deriving constitutive models for soils. The paper develops a thermodynamically consistent set of variables that describe the state of the soil. It shows the formulation of plasticity models using fundamental physical concepts of work, energy and dissipation. Analysing a number of basic well-known models, such as the DruckerPrager and MCC models, the paper highlights their shortcomings in terms of satisfying basic thermomechanical principles, and proposes a family of new models where these principles are satisfied. Although this is not yet a widespread framework for modelling soils, it is fundamentally consistent, and could prove more applicable in the future.

\section{MODERN NUMERICAL ANALYSIS}

After the initial, mainly elastic, numerical analyses of geotechnical problems, the 1980s saw much greater application of numerical analysis to real geotechnical problems. These applications range from investigating the behaviour of laboratory and field experiments to understanding the mechanisms of behaviour of real geotechnical structures.

\section{Laboratory and field applications}

In terms of laboratory experiments, the work of Potts et al. (1987) reported on the use of finite element analysis in understanding stress and strain non-uniformities in the material tested in a direct shear box apparatus and what effect these have on the interpretation of shear box experiments. Arroyo et al. (2006) showed three-dimensional finite difference analyses of axial wave propagation through a triaxial soil sample, thus simulating bender element tests for measuring elastic soil stiffness. The results have significant implications for laboratory testing, as they indicate that the 
size of the sample affects the propagating signal owing to reflections from the lateral boundaries of the sample. Errors in shear velocity estimates could therefore be introduced by the slender geometry of a sample, high wavelengths, reflecting boundaries and low material attenuation. The implication of the results is that certain experimental details need to be carefully considered before bender element testing can be taken into consideration with more certainty.

The trapdoor problem is often considered suitable for investigating problems that involve active or passive failure in the soil, such as arching around tunnels in the former, or the uplift force of buried anchors in the latter case. Koutsabeloulis \& Griffiths (1989), using a non-associated Mohr-Coulomb model, investigated the two modes of trapdoor failure in both plane-strain and axisymmetric conditions and presented the results in the form of non-dimensional influence charts of a range of soil properties, trapdoor sizes and layer thickness. Sloan et al. (1990), using finite element limit analysis (i.e. upper and lower bounds), investigated the undrained stability of a trapdoor problem (i.e. Tresca soil), bracketing the exact solutions to within $10 \%$ or better for a range of trapdoor geometries. This is the first application of this hybrid method of analysis reported in Géotechnique.

Teh \& Houlsby (1991), utilising the strain path method and large-displacement finite element analysis, investigated the quasi-static penetration of a cone penetrometer into clay, which was modelled as a von Mises soil. The findings emphasised the primary importance of the soil rigidity index $I_{\mathrm{r}}$ and the horizontal stress in the ground in influencing the cone factor $N_{\mathrm{kt}}$. The authors therefore proposed an equation relating $N_{\mathrm{kt}}$ to soil parameters and cone roughness. Lu et al. (2004) investigated cone penetration into a Tresca soil using large-displacement finite element analysis, but introducing a novel approach of 'arbitrary Lagrangian-Eulerian' largedisplacement analysis. An expression for the cone factor $N_{\mathrm{kt}}$ was also proposed in terms of soil rigidity, cone roughness and stresses in the ground, which compared well with the previous proposal of Teh \& Houlsby, giving confidence in its application in practice. In a similar way, Houlsby \& Carter (1993) made use of a parametric FE study to investigate the effects of the geometry of the self-boring pressuremeter on the interpretation of this field test. The effects of length-todiameter ratio $(L / D)$ and penetration depth-to-diameter ratio $(H / D)$ were examined, together with the soil rigidity index. The results were presented as a chart of correction factors for strengths derived from pressuremeter tests, which can be applied in practice.

\section{Shallow foundations}

In terms of real geotechnical problems, the behaviour of foundations, both shallow and deep, has been extensively studied and reported in Géotechnique. The bearing capacity of shallow foundations is normally calculated in practice using Terzaghi's bearing capacity equation, which takes account of footing geometry, embedment depth and load inclination. However, most of the load factors in this equation are empirical, and several different expressions for each of these have been adopted in practice over the years. Griffiths (1982) showed how the FE method can be applied for obtaining theoretically accurate values of bearing capacity factors $N_{\mathrm{c}}, N_{\mathrm{q}}$ and $N_{\gamma}$, utilising the Mohr-Coulomb constitutive model. It was shown that the numerical values are closer to the lower empirical values, and also that $N_{\gamma}$ depends on the footing roughness. More recently, using the FE limit analysis approach, Salgado et al. (2004) performed a comprehensive study of the undrained bearing capacity of general foundation shapes. Full three-dimensional analyses of embedded square, circular and rectangular foundations, as well as two-dimensional analyses of embedded strip foundations were performed, with proposed finite values of shape and depth factors. Embedment depths of five times the footing width/diameter $(B)$ were considered. The maximum difference between upper- and lower-bound solutions was not more than $12 \%$, except for the circular footing with the maximum embedment depth of $5 B$, for which it reached $25 \%$. Consequently, the solutions can be taken as sufficiently accurate for engineering practice. This approach was recently extended to footings on sand (Lyamin et al., 2007), and a different form of the bearing capacity equation was proposed that does not rely on the traditional approximation that the effects of foundation shape and depth can be considered separately for each of the effects of soil self-weight and surcharge (embedment).

Since the early 1990 s, foundation design has seen a move from the classical bearing capacity equation towards the consideration of individual loading components (i.e. horizontal force $H$, vertical force $V$ and moment $M$ ). This has seen the formulation of a three-dimensional loading surface in $H-V-M$ stress space that is a boundary to possible and impossible loading combinations for a particular footing. The first numerical evidence of such formulation published in Géotechnique is that of Bransby \& Randolph (1998), who showed the results and mechanisms from general undrained loading of a surface strip footing on a Tresca soil, which allowed tension to develop between the footing and the soil. The authors proposed equations for various cross-sections of the loading surface that can be directly applied in practice. In a similar study, Taiebat \& Carter (2000) investigated failure envelopes for general undrained loading of a surface circular footing on a Tresca soil, which also mobilised full tension in the interface with the soil.

Martin \& Houlsby (2001) took the concept of a threedimensional loading surface to formulate a macro model of a footing and soil. They described the load-displacement response of a spudcan footing on clay as a plasticity model with three degrees of freedom (vertical, rotational and horizontal). This model, named 'model B', has a threedimensional loading surface as a yield surface, as well as a flow rule, both derived from laboratory experiments of a model footing on kaolin. The behaviour inside the yield surface is described by elastic stiffness factors determined from $\mathrm{FE}$ analyses, while upon reaching the yield surface the model can harden or soften according to a hardening rule. The idea is that such a macro model can be used in a simplified structural analysis of a jack-up rig, for example, where the footing and the soil at the end of jack-up legs can be represented with this macro model. Houlsby \& Cassidy (2002) developed a similar concept, called 'model C', for footings on sand.

Adopting a similar approach, Zdravkovic et al. (2001) investigated the pull-out capacity of suction caissons in soft clay, utilising the advanced constitutive model MIT-E3, which can take account of soil strength anisotropy. Realistic anisotropy, from laboratory experiments in the hollow cylinder apparatus, was input into the model. Similar to the studies described above, the authors derived a predictive equation and interaction charts for determining the pull-out capacity of suction caissons. In addition, for the first time in Géotechnique the effect of soil strength anisotropy, in this case on the pull-out capacity, was demonstrated and quantified. It shows that the pull-out capacity of a suction caisson can be significantly overestimated if the soil is considered isotropic.

\section{Piles}

Investigations of piled foundations began by phenomenological investigations of pile installation effects on lateral 
stresses and pore water pressures in the ground. Randolph et al. (1979) used the FE method to simulate pile installation in clay as a cavity expansion problem, and Potts \& Martins (1982) investigated pile loading by applying increments of vertical displacement along the boundary of the pile shaft. Clearly, these were the first attempts in looking at single pile behaviour, but piles are normally placed in a group, and the main issues become their interaction, and transfer of the load between individual piles and the pile cap. In recent years insight into these issues and guidance for practical design have been offered by Horikoshi \& Randolph (1998) and then by Reul \& Randolph (2003). In the former publication the authors investigated for the first time in Géotechnique the concept of piled raft foundations. They used a relatively simple approach of a plate on piles, utilising Mindlin's solution, and validated it against the case study from the centrifuge. The optimum design was established in terms of reducing differential settlements, with the following guidelines.

(a) Piles should be distributed over the central area of the raft.

(b) The stiffness of the pile group should be approximately equal to the stiffness of the raft alone.

(c) The total pile capacity should be designed for between $40 \%$ and $70 \%$ of the design load.

In the latter publication the authors performed three-dimensional FE back-analyses of well-instrumented piled raft foundations in overconsolidated clay. Having obtained good agreement between numerical analyses and field measurements, the authors performed further studies with altered pile distributions below the raft, confirming that the central distribution of piles below the raft reduces both the settlement and the differential settlement, as well as increases the raft's participation in carrying the load.

\section{Retaining structures}

The finite element method has been used to examine conventional retaining wall design in the work of Potts \& Fourier (1984), showing, among other things, that classical limit equilibrium design underestimates structural forces for excavations in front of a single propped retaining wall in high- $K_{0}$ soils (such as London Clay). In a similar way, Powrie \& Li (1991) investigated a type of retaining wall that is propped at formation level, in terms of soil/wall/prop stiffness and initial $K_{0}$ in the soil. Géotechnique has also reported work on three-dimensional modelling of the diaphragm wall panel installation procedure, where the soil is first excavated for the panel, and then bentonite pressure is applied on the excavation surfaces before concreting (Gourvenec \& Powrie, 1999; Ng \& Yan, 1999). The effect of panel length on horizontal ground movements and changes in stress distribution in the ground was investigated. More recently, Zdravkovic et al. (2005) investigated modelling issues related to a retaining wall in a three-dimensional analysis. The authors demonstrated that the current approach of modelling the wall with isotropic properties in all coordinate directions is not realistic, and predicts ground and wall movements much smaller than those that are likely to occur in reality. These walls normally cannot transmit any substantial bending, and transmit only very small axial force in the horizontal direction. They also investigated issues of rectangular excavations being analysed as plane-strain or axisymmetric problems, and how such solutions apply to a general three-dimensional geometry.

\section{Tunnelling}

In terms of tunnelling, the main issue has been the prediction of realistic settlement troughs above tunnels, in particular for high $K_{0}$ soils. Lee \& Rowe (1989) reported that elastic isotropic models predict settlement troughs that are too shallow and too wide. Using the FE method for simulating tunnel excavation, their results indicate that elastic soil anisotropy should be taken into account and that, in particular, care should be given to selection of the ratio of $G_{\mathrm{vh}}$ to $E_{\mathrm{v}}$. Franzius et al. (2005) investigated this further in three-dimensional analyses of tunnel excavations in London Clay (a high- $K_{0}$ material), utilising non-linear elastic smallstrain anisotropy and comparing the results for the transversal settlement trough in a cross-section along the tunnel with the results from a plane-strain analysis. The authors showed that three-dimensional modelling has negligible effects on the transverse surface settlement trough, but that longitudinal settlements do not develop a steady state. Transverse settlements improved with the use of an unrealistically high degree of stiffness anisotropy, but longitudinal settlements reached steady state only when, in addition to this, a low $K_{0}$ was introduced in the vicinity of the tunnel. However, both assumptions were unreasonable for London Clay, and resulted in the analysis predicting a volume loss that was too high. In general, simulation of tunnelling in high- $K_{0}$ soils still needs further investigation, and is a headache for many analysts. Shin et al. (2002) proposed a novel method for modelling the coupled behaviour of a tunnel lining, in an attempt to investigate the effects of tunnel lining permeability on ground movements and on load distribution on the lining. The method involves coupling of beam elements (to represent the structural properties of the lining) and thin solid elements (on the soil side of the lining, to represent its hydraulic properties). Cases of high- and low-permeability soils were considered, with flow regimes that either do or do not draw down the phreatic surface, and in which tunnel lining is either fully permeable or impermeable. The results showed significant interaction between the soil and lining permeabilities and, consequently, a significant effect on ground movements and loads in the lining in the long term, agreeing well with limited observations from low-permeability soils such as London Clay. Schroeder et al. (2004) looked at another practical problem of the effect of new piles, installed around existing tunnels, on tunnel loading and deformation. This is a very common problem in cities such as London, where new developments have to conform to very strict rules imposed by London Underground Ltd for their infrastructure tunnels. The authors produced design guidelines that relate tunnel deformation to the minimum distance between the first row of piles and the existing tunnel.

\section{Embankments and slopes}

The role of progressive failure in general slope stability was quantified for the first time in Géotechnique in the paper by Potts et al. (1990), which described the failure of Carsington dam in the UK. Classical limit equilibrium analysis of this dam showed a sufficient factor of safety for its stability. However, the dam failed during construction, and finite element analysis performed by the authors, utilising a non-linear strain-softening elasto-plastic material model, revealed that progressive failure of a brittle clay layer in the dam foundations was the cause of dam failure. Potts et al. (1997) applied a similar method of analysis to explain the delayed collapse of cut slopes in stiff clays, with particular reference to London Clay. By considering various typical heights and inclinations of slopes, and also surface hydraulic boundary conditions, the authors were able to predict the 
time to failure. The findings from this paper have significant implications for the stability of cut slopes in London Clay along motorways and railway lines.

For embankments on soft, normally consolidated soil, the issue for design is often the choice of undrained strength for the foundation soil. As the potential slip surface engages stress states ranging from plane-strain compression through simple shear to plane-strain extension, design practice often recommends that a simple shear strength be taken for calculating failure height. Zdravkovic et al. (2002) investigated this issue for the case study of a real embankment brought to failure, using finite element analysis and an anisotropic soil constitutive model, MIT-E3. By comparing the results from isotropic and anisotropic analyses, the authors demonstrated that the back-analysed soil strength at embankment failure, using an isotropic constitutive model, is not necessarily applicable for further design or redesign of an embankment if the soil is highly anisotropic. The new design can be largely conservative or non-conservative, depending on the shape and size of the new embankment. Consequently, if the isotropic soil strength has to be used, which is most likely in a design office scenario, it needs to be averaged in a certain way.

\section{CONCLUSIONS}

This review of numerical analysis and constitutive model developments published in Géotechnique has revealed several important points.

(a) Numerical analysis and constitutive modelling clearly involve significant use of mathematical techniques. Despite this, many major geotechnical developments in this area have been published in Géotechnique and not in numerical methods journals.

(b) It is evident that the development of constitutive models has advanced significantly more than their application in routine numerical analysis. The most advanced constitutive models (such as MIT-E3, kinematic surface models, and unsaturated models) exist only in research software, and are still a long way from being used commercially. One of the reasons for this is that they require significantly more input parameters, which in turn require special testing, and are therefore not suitable for everyday design.

(c) It is also evident that, in general, the numerical analyses of geotechnical problems presented in Géotechnique have almost always investigated practical issues, and have aimed to provide guidance and improved methods for design. Modern numerical analysis has certainly enabled geotechnical practice to understand mechanisms of soil behaviour underneath structures and construction processes that are of increasing complexity.

Potts (2003), in his Rankine lecture, posed a very pertinent question about what is at present the real role of numerical analysis and constitutive modelling in geotechnical practice. Through various examples he demonstrated the advantages and pitfalls of using numerical analysis, recognising that numerical analysis will increasingly become the preferred design tool in the future. However, going back to the warning message quoted at the beginning of this review, Potts also warned that useful numerical analysis can be performed only if one fully understands both the numerical tool and the real soil behaviour!

\section{REFERENCES}

Alonso, E. E., Gens, A. \& Josa A. (1990). A constitutive model for partially saturated soils. Géotechnique 40, No. 3, 405-430.

Arroyo, M., Muir Wood, D., Greening, P. D., Medinas, L. \& Rio, J. (2006). Effects of sample size on bender-based axial $G_{0}$ measurements. Géotechnique 56, No. 1, 39-52.

Baudet, B. \& Stallebrass, S. (2004). A constitutive model for structured clays. Géotechnique 54, No. 4, 269-278.

Been, K. \& Jefferies, M. G. (1985). A state parameter for sands. Géotechnique 35, No. 2, 99-112.

Bishop, A. W. (1955). The use of the slip circle in the stability analysis of slopes. Géotechnique 5, No. 1, 7-17.

Bolzon, G., Schrefler, B. A. \& Zienkiewicz, O. C. (1996). Elastoplastic soil constitutive laws generalised to partially saturated states. Géotechnique 46, No. 2, 279-289.

Borja, R. I. \& Kavazanjian, E. (1985). A constitutive model for the stress-strain-time behaviour of 'wet' clays. Géotechnique $\mathbf{3 5}$, No. 3, 283-298.

Bransby, M. F. \& Randolph, M. F. (1998). Combined loading of skirted foundations. Géotechnique 48, No. 5, 637-655.

Cheng, Y. P., Nakata, Y. \& Bolton, M. D. (2003). Discrete element simulation of crushable soil. Géotechnique 53, No. 7, 633-641.

Collins, I. F. \& Kelly, P. A. (2002). A thermomechanical analysis of a family of soil models. Géotechnique 52, No. 7, 507-518.

Cui, L. \& O'Sullivan, C. (2006). Exploring the macro- and microscale response of an idealised granular material in the direct shear apparatus. Géotechnique 56, No. 7, 455-468.

Cundal, P. A. \& Strack, O. D. L. (1979). A discrete numerical model for granular assemblies. Géotechnique 29, No. 1, 47-65.

Franzius, J. N., Potts, D. M. \& Burland, J. B. (2005). The influence of soil anisotropy and $K_{0}$ on ground surface movements resulting from tunnel excavation. Géotechnique 55, No. 3, 189-199.

Gibson, R. E. (1958). The progress of consolidation in a clay layer increasing in thickness with time. Géotechnique 8, No. 4, 171182.

Gibson, R. E. (1967). Some results concerning displacements and stresses in a non-homogeneous elastic half-space. Géotechnique 17, No. 1, 58-67.

Gibson, R. E. (1974). The analytical method in soil mechanics. Géotechnique 24, No. 2, 115-140.

Griffiths, D. V. (1982). Computation of bearing capacity factors using finite elements. Géotechnique 32, No. 3, 195-202.

Gourvenec, S. M. \& Powrie, W. (1999). Three-dimensional finiteelement analysis of diaphragm wall installation. Géotechnique 49, No. 6, 801-823.

Henkel, D. J. (1960). The relationships between the effective stresses and water content in saturated clays. Géotechnique $\mathbf{1 0}$, No. 2, 41-54.

Horikoshi, K. \& Randolph, M. F. (1998). A contribution to optimum design of piled rafts. Géotechnique 48, No. 3, 301-317.

Houlsby, G. T. \& Carter, J. P. (1993). The effects of pressuremeter geometry on the results of tests in clay. Géotechnique 43, No. 4, $567-576$.

Houlsby, G. T. \& Cassidy, M. J. (2002). A plasticity model for the behaviour of footings on sand under combined loading. Géotechnique 52, No. 2, 117-129.

Jardine, R. J., Potts, D. M., Fourier, A. B. \& Burland, J. B. (1986). Studies of the influence of non-linear stress-strain characteristics in soil-structure interaction. Géotechnique 36, No. 3, 377-396.

Kavvadas, M. \& Amorosi, A. (2000). A constitutive model for structured soils. Géotechnique 50, No. 3, 263-273.

Khalili, N. \& Khabbaz, M. H. (1998). A unique relationship for the determination strength of unsaturated soils. Géotechnique 48, No. 5, 681-687.

Koutsabeloulis, N. C. \& Griffiths, D. V. (1989). Numerical modelling of the trap door problem. Géotechnique 39, No. 1, 77-89.

Latham, J.-P., Lu, Y. \& Munjiza, A. (2001). A random method for simulating loose packs of angular particles using tetrahedra. Géotechnique 51, No. 10, 871-879.

Lee, K. M. \& Rowe, R. K. (1989). Deformations caused by surface loading and tunnelling: the role of elastic anisotropy. Géotechnique 39, No. 1, 125-140.

Lin, X. \& Ng, T.-T. (1997). A three-dimensional discrete element model using arrays of ellipsoids. Géotechnique 47, No. 2, 319329. 
Little, A. L. \& Price, V. E. (1958). The use of an electronic computer for slope stability analysis. Géotechnique 8, No. 3, $113-120$.

Lu, Q., Randolph, M. F., Hu, Y. \& Bugarski, I. C. (2004). A numerical study of cone penetration in clay. Géotechnique 54, No. 4, 257-267.

Lyamin, A. V., Salgado, R., Sloan, S. W. \& Prezzi, M. (2007). Twoand three-dimensional bearing capacity of footings in sand. Géotechnique 57, No. 8, 647-662.

Manzari, M. T. \& Dafalias, Y. F. (1997). A critical state two-surface plasticity model for sands. Géotechnique 47, No. 2, 255-272.

Martin, C. M. \& Houlsby, G. T. (2001). Combined loading of spudcan foundations on clay: numerical modelling. Géotechnique 51, No. 8, 687-699.

Milovic, D. M., Touzot, G. \& Tournier, J. P. (1970). Stresses and displacements in an elastic layer due to inclined and eccentric load over a rigid strip. Géotechnique 20, No. 3, 231-252.

Mroz, Z., Norris, V. A. \& Zienkiewicz, O. C. (1979). Application of an anisotropic hardening model in the analysis of elastoplastic deformation of soils. Géotechnique 29, No. 1, 1-34.

Muhlhaus, H.-B. \& Vardoulakis, I. (1987). The thickness of shear bands in granular materials. Géotechnique 37, No. 3, 271-283.

Ng, C. W. W. \& Yan, R. W. M. (1999). Three-dimensional modelling of a diaphragm wall construction sequence. Géotechnique 49, No. 6, 825-834.

Pender, M. J. (1978). A model for the behaviour of overconsolidated soil. Géotechnique 28, No. 1, 1-25.

Potts, D. M. (2003). Numerical analysis: a virtual dream or practical reality? Géotechnique 53, No. 6, 535-573.

Potts, D. M. \& Fourier, A. B. (1984). The behaviour of a propped retaining wall: results of a numerical experiment. Géotechnique 34, No. 3, 383-404.

Potts, D. M. \& Martins, J. P. (1982). The shaft resistance of axially loaded piles in clay. Géotechnique 32, No. 4, 369-386.

Potts, D. M., Dounias, G. T. \& Vaughan, P. R. (1987). Finite element analysis of the direct shear box test. Géotechnique 37, No. $1,11-23$.

Potts, D. M., Dounias, G. T. \& Vaughan, P. R. (1990). Finite element analysis of progressive failure of Carsington embankment. Géotechnique 40, No. 1, 79-101.

Potts, D. M., Kovacevic, N. \& Vaughan, P. R. (1997). Delayed collapse of cut slopes in stiff clay. Géotechnique 47, No. 5, 953-982.

Poulos, H. G. (1968). Analysis of settlement of pile groups. Géotechnique 18, No. 4, 449-471.

Poulos, H. G. \& Davis, E. H. (1968). The settlement behaviour of single axially loaded incompressible piles and piers. Géotechnique 18, No. 3, 351-371.

Powrie, W. \& Li, E. S. F. (1991). Finite element analysis of an in situ wall propped at formation level. Géotechnique 41, No. 4, 499-514.

Randolph, M. F., Carter, J. P. \& Wroth, C. P. (1979). Driven piles in clay: the effect of installation and subsequent consolidation Géotechnique 29, No. 4, 361-393.

Reul, O. \& Randolph, M. (2003). Piled rafts in overconsolidated clay: comparison of in situ measurements and numerical analyses. Géotechnique 53, No. 3, 301-315.

Roscoe, K. H., Schofield, A. N. \& Wroth, C. P. (1958). On the yielding of soils. Géotechnique 8, No. 1, 22-53.

Rouainia, M. \& Muir Wood, D. (2000). A kinematic hardening constitutive model for natural clays with loss of structure. Géotechnique 50, No. 2, 153-164.

Salgado, R., Lyamin, A. V., Sloan, S. W. \& Yu, H. S. (2004). Twoand three-dimensional bearing capacity of foundations in clay. Géotechnique 54, No. 5, 297-306

Schroeder, F. C., Potts, D. M. \& Addenbrooke, T. I. (2004). The influence of pile group loading on existing tunnels. Géotechnique 54, No. 6, 351-362.

Shin, J. H., Addenbrooke, T. I. \& Potts, D. M. (2002). A numerical study of the effect of groundwater movement on long-term tunnel behaviour. Géotechnique 52, No. 6, 391-403.

Simpson, B. (1992). Retaining structures: displacement and design. Géotechnique 42, No. 4, 541-576.

Simpson, B., O'Riordan, N. J. \& Croft, D. D. (1979). A computer model for the analysis of ground movements in London Clay. Géotechnique 29, No. 2, 149-175.

Sloan, S. W., Assadi, A. \& Purushothaman, N. (1990). Undrained stability of a trapdoor. Géotechnique 40, No. 1, 45-62.

Smith, I. M. (1970). Incremental numerical solution of a simple deformation problem in soil mechanics. Géotechnique 20, No. 4, $357-372$.

Smith, I. M. \& Hobbs, R. (1974). Finite element analysis of centrifuge and built-up slopes. Géotechnique 24, No. 4, 531-559.

Smith, I. M. \& Hobbs, R. (1976). Biot analysis of consolidation beneath embankments. Géotechnique 26, No. 1, 149-171.

Stallebrass, S. E. \& Taylor, R. N. (1997). The development and evaluation of a constitutive model for the prediction of ground movements in overconsolidated clay. Géotechnique 47, No. 2, $235-253$.

Taiebat, H. A. \& Carter, J. P. (2000). Numerical studies of the bearing capacity of shallow foundations on cohesive soil subjected to combined loading. Géotechnique 50, No. 4, 409-418.

Teh, C. I. \& Houlsby, G. T. (1991). An analytical study of the cone penetration test in clay. Géotechnique 41, No. 1, 17-34.

Thornton, C. (1979). The conditions for failure of a face-centred cubic array of uniform rigid spheres. Géotechnique 29, No. 4, $441-459$.

Thornton, C. (2000). Numerical simulation of deviatoric shear deformation of granular media. Géotechnique 50, No. 1, 43-53.

Tomlin, G. R. (1966). Seepage analysis through zoned anisotropic soils by computer. Géotechnique 16, No. 3, 220-230.

Van Eekelen, H. A. M. \& Potts, D. M. (1978). The behaviour of Drammen clay under cyclic loading. Géotechnique 28, No. 2, 173-196.

Wheeler, S. J. \& Sivakumar, V. (1995). An elasto-plastic critical state framework for unsaturated soil. Géotechnique 45, No. 1, 35-53.

Whittle, A. J. (1993). Evaluation of constitutive model for overconsolidated clays. Géotechnique 43, No. 2, 289-313.

Wroth, C. P. \& Bassett, R. H. (1965). A stress-strain relationship for the shearing behaviour of a sand. Géotechnique 15, No. 1, 32-56

Yin, J.-H. \& Graham, J. (1996). Elastic visco-plastic modelling of one-dimensional consolidation. Géotechnique 46, No. 3, 515527.

Zdravkovic, L., Potts, D. M. \& Jardine, R. J. (2001). A parametric study of the pull-out capacity of bucket foundations in soft clay. Géotechnique 51, No. 1, 55-67.

Zdravkovic, L., Potts, D. M. \& Hight, D. W. (2002). The effect of strength anisotropy on the behaviour of embankments on soft ground. Géotechnique 52, No. 6, 447-457.

Zdravkovic, L., Potts, D. M. \& St John, H. D. (2005). Modelling of a 3D excavation in finite element analysis. Géotechnique 55, No. 7, 497-513.

Zhang, L. \& Thornton, C. (2007). A numerical examination of the direct shear test. Géotechnique 57, No. 4, 343-354.

Zienkiewicz, O. C., Humpheson, C. \& Lewis, R. W. (1975). Associated and non-associated visco-plasticity in soil mechanics. Géotechnique 25, No. 4, 671-689.

Zienkiewicz, O. C., Valliappan, S. \& King, I. P. (1968). Stress analysis of rock as a 'no tension' material. Géotechnique $\mathbf{1 8}$, No. $1,56-66$ 